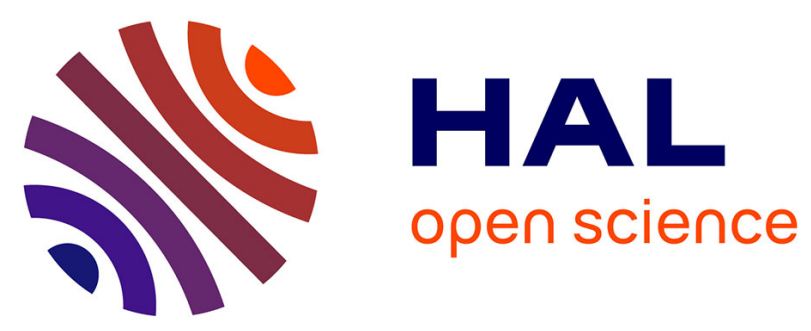

\title{
Different constraints on grip selection in brain-damaged patients. Object use versus object transport.
}

François Osiurak, Ghislaine Aubin, Philippe Allain, Christophe Jarry, Frédérique Etcharry-Bouyx, Isabelle Richard, Didier Le Gall

\section{- To cite this version:}

François Osiurak, Ghislaine Aubin, Philippe Allain, Christophe Jarry, Frédérique Etcharry-Bouyx, et al.. Different constraints on grip selection in brain-damaged patients. Object use versus object transport.. Neuropsychologia, 2008, 46, pp.2431-2434. halshs-00485314

\section{HAL Id: halshs-00485314 \\ https://shs.hal.science/halshs-00485314}

Submitted on 20 May 2010

HAL is a multi-disciplinary open access archive for the deposit and dissemination of scientific research documents, whether they are published or not. The documents may come from teaching and research institutions in France or abroad, or from public or private research centers.
L'archive ouverte pluridisciplinaire HAL, est destinée au dépôt et à la diffusion de documents scientifiques de niveau recherche, publiés ou non, émanant des établissements d'enseignement et de recherche français ou étrangers, des laboratoires publics ou privés. 


\title{
Different constraints on grip selection in brain-damaged patients. Object use versus object transport.
}

\author{
François Osiurak $^{1,2}$, Ghislaine Aubin ${ }^{1,2,3}$, Philippe Allain ${ }^{1,2}$, Christophe Jarry ${ }^{1,2}$, \\ Frédérique Etcharry-Bouyx $^{1,2}$, Isabelle Richard ${ }^{3}$, Didier Le Gall ${ }^{1,2}$ \\ ${ }^{1}$ Laboratory of Psychology UPRES EA 2646, University of Angers, France. \\ ${ }^{2}$ Neuropsychological Unit, Department of Neurology, University Hospital of Angers, France. \\ ${ }^{3}$ Regional Centre for Functional Rehabilitation of Angers, France.
}

Correspondence address:

Didier Le Gall

Unité de Neuropsychologie

Département de Neurologie

Centre Hospitalier Universitaire

4, rue Larrey

49033 Angers Cedex 01

France

Tel: 33 (0) 241354614

Fax: 33 (0) 241353594

E-Mail: DiLeGall@chu-angers.fr

Running head: Object use versus object transport 


\begin{abstract}
The present study discusses the presence of different constraints on action selection during object use versus object transport. Sixteen left brain-damaged (LBD) patients, 10 right braindamaged (RBD) and 35 healthy controls were examined on a grip preference test consisting of a grasping-to-transport and a grasping-to-use condition. Assessment included a general praxis testing (pantomime production, object utilization gesture recognition and object use). We also reported the case of a close-head injury patient (DR) with an atypical behavioural pattern. Our results supported the different constraint hypothesis. While several LBD and RBD patients performed inappropriate grips in the grasping-to-transport condition, only two patients (L2 and DR) used inappropriate grips in the grasping-to-use condition. No correlation was found between the two conditions of the grip preference test and measures of the general praxis testing. The discussion focuses on the nature of constraints on grip selection during object use and object transport.
\end{abstract}

Keywords: Tool use; Apraxia; Action; Motor control; Grasping; Pantomime. 


\section{Introduction}

Although conceived as a human feature, tool use is nevertheless generally considered as the logical extension of the ability of non-human primates to make hand-object interactions. In this frame, Johnson-Frey and Grafton (2003) recently proposed two classes of schemas.

First, acting on objects (e.g., moving a scissors from one place to another) would involve schemas for transforming sensory information into one of a potentially set of postures suitable for achieving a stable grip for transportation. Rosenbaum et al. (1990) demonstrated that healthy subjects grasp objects to be moved from one location to another in a way that affords a comfortable final rather than an initial posture. On the basis of these results and other related studies (e.g., Rosenbaum, Vaughan, Barnes, \& Jorgensen, 1992), Rosenbaum, Meulenbroek, Vaughan, and Jansen (2001) supported the finding that postural end states are known before movements begin, thus suggesting the existence of representations of goal postures that would constrain the course of movements.

Second, when acting with objects (e.g., using scissors to cut paper), posture selection would be guided by schemas that consist of parameters for manipulating objects in the precise and overlearned postures necessary to use them. This agrees with the gesture engram hypothesis that has been extensively investigated in the field of apraxia, which is a disorder of skilled movement (Rothi, Ochipa, \& Heilman, 1991).

The "different constraint hypothesis" advanced by Johnson-Frey and Grafton (2003) is essentially based on recent work in functional neuroimaging, and there is no clear behavioural evidence that the two classes of hand-object interactions can be separately impaired. For instance, by investigating left brain-damaged (LBD) and right brain-damaged (RBD) patients, Hermsdörfer, Laimgruber, Kerkhoff, Mai, and Goldenberg (1999) did not report any relationship between apraxia and the ability to plan comfortable final postures in a graspingto-transport condition. However, apraxia was assessed by asking subjects to imitate 
meaningless postures, a situation that would not require access to gesture engrams (Goldenberg, 1999). Buxbaum, Johnson-Frey, and Bartlett-Williams (2005) found strong associations between pantomime production and recognition, and the ability to plan comfortable initial postures in a grasping-only condition. Nonetheless, this latter condition induced mental imagery and, as they conceded, their data could not rule out the possibility that the associations they found did not reveal deficient ability to generate mental images. So, given the lack of behavioural evidence in favour of the different constraint hypothesis, one could speculate that the same constraints (hereafter called the "same constraint hypothesis") guide the posture selection in object use or object transport (see, e.g., the "thumb-toward bias", Rosenbaum et al., 1992).

The present work aims to provide behavioural data to test the different constraint hypothesis versus the same constraint hypothesis. Sixteen LBD patients, 10 RBD patients and 35 healthy controls were examined on a grip preference test in which a dowel had to be grasped and transported in various locations ("grasping-to-transport condition"). We developed a second condition in which familiar objects had to be grasped and used ("grasping-to-use condition"). Subjects also performed a general praxis testing. To contribute to the discussion, we reported the case of a close-head injury patient (DR) with an atypical behavioural pattern (see below). The different constraint hypothesis predicts only the association between the grasping-to-use condition and the general praxis testing. The same constraint hypothesis predicts the association between all measures.

\section{Methods}

\subsection{Participants}

Sixteen LBD patients, 10 RBD patients and 35 healthy controls participated in the study (Table 1). All LBD and RBD patients suffered a first unilateral cerebral vascular accident. Given the rarity of his behavioural profile (see below), we reported the case of the patient DR 
(37 years old, 9 years of education, right-handed) who suffered a close-head injury due to domestic accident. A CT scan two weeks after the accident revealed haemorrhage contusion of the left fronto-temporo-parietal region. He showed neither elementary sensory-motor deficit, nor evidence of any forms of visuo-spatial deficit. All participants had no previous history of neurological or psychiatric illnesses. The study was conducted in accordance with the Declaration of Helsinki.

\subsection{Grip preference}

Grasping-to-transport condition. Participants sat at a table upon which was fastened a cradle that included two supports (Fig. 1). A black-and-white wooden dowel (length $32 \mathrm{~cm}$, diameter $2 \mathrm{~cm}$ ) laid on supports with the black end on the left support. To each side of the dowel laid a black and a white disk (diameter $3 \mathrm{~cm}$ ). Participants began each trial with the hand resting in a neutral orientation (thumb pointing to 12 o'clock). When the examiner pointed to a black (white) disk, subjects were required to pick up the dowel and place the black (white) end squarely on the black (white) disk. Each disk was pointed 5 times, totalling 20 trials. Subjects were told to use a power grip and not to twirl the dowel. To prevent subjects from seeing appropriate grips, the examiner moved the dowel by holding it between the index and the middle finger of each hand, with the palms facing each other. Two final postures were distinguished at the moment the dowel was placed on the disk. A comfortable final posture corresponded to the thumb pointing up, and an uncomfortable final posture to the thumb pointing down. Two initial grips were distinguished at the moment the dowel was grasped: An overhand or an underhand grip (Rosenbaum et al., 1990). 
Fig. 1 about here

Grasping-to-use condition. Participants sat at a table upon which were placed a familiar object (e.g., hammer) and the corresponding recipient (nail). Participants began each trial with the hand resting on the tabletop in a palm down position (Fig. 1). The participants' thumb pointed to either the 3 o'clock (participants using their left hand) or the 9 o'clock position (participants using their right hand). Subjects were required to pick up the object with a power grip and to demonstrate how they use it with the recipient. It was stressed that the grip should remain unaltered once the object picked up. Object orientation was manipulated (the handle toward versus away from the participant). To prevent subjects from seeing appropriate grips, the examiner moved the objects by holding them between the index and the middle finger of each hand, with the palms facing each other. Each object (see Table 2) was presented 4 times in each orientation totalling 64 trials ( 8 objects/recipients $\times 2$ orientations $\times 4$ trials). Two handgrips were identified. A "thumb-toward" grip occurred if the handle was grasped with the (base of the) thumb toward the specific part of the object (e.g., the head of a hammer). A "thumb-away" grip occurred if the handle was grasped with the thumb away from the specific part. Since subjects were asked to use power grips, thumb-toward grips were considered to provide a more comfortable posture than thumb-away grips. We were also concerned about the effectiveness of object use. Since an incorrect grip choice could involve awkwardness, 1 point was given when the action was achieved even with awkward manipulations. No point was given if the action was not achieved.

\subsection{General praxis testing}

Object use. Ten familiar objects and their corresponding recipients were placed in front of the subject. Subjects were asked to grasp the object and to demonstrate how they use it. 
Performance was rated on a 3-point scale: $0=$ action not achieved; $1=$ correct use after unsuccessful trials or clumsy performance; $2=$ correct (Goldenberg \& Hagmann, 1998). Maximum score was 20 points.

Pantomime production. Subjects were required to pantomime 10 actions (the same as in the object use test) to the sight of objects and in imitation. Performance was rated on a 3-point scale: $0=$ unable/gross errors; $1=$ possible errors; $2=$ correct (Sunderland $\&$ Sluman, 2000). Maximum score was 20 points for each condition.

Object utilization gesture recognition. This test (Bergego, Pradat-Diehl, Deloche, Durand, \& Lauriot-Prevost, 1992) consisted of 20 sets of four photographs. In each set, one photograph depicted the correct use of the object, whereas the remaining three photographs showed the object incorrectly oriented, inappropriately held or used as another object. One point was credited for each correct response, totalling 20 points.

\section{Results}

All brain-damaged patients used their ipsilesional hand. Eighteen controls used their right hand and 17 their left hand. Since no difference emerged in the use of either hand, the scores of the two control subgroups were pooled together.

\subsection{Grip preference}

\subsubsection{Grasping-to-transport condition}

Controls performed significantly more comfortable final postures than RBD and LBD patients (Table 1). However, both groups did not differ from each other. To analyse the incidence of overhand and underhand grips, the data from each group of patients were pooled across all participants and analysed by a chi-square procedure. This analysis concerned only patients who performed at least one uncomfortable final posture, that is, $8 \mathrm{RBD}$ patients $(n=$ $160)$ and 10 LBD patients $(n=200)$. This restriction was chosen because no control subjects 
scored below 19/20. In the RBD group, the distribution of overhand ( $n=69 / 160$ ) and underhand $(n=91 / 160)$ grips did not differ significantly from chance $\left(\chi^{2}=3.03, p=.08\right)$. The LBD patients exhibited clear initial grip preference $\left(\chi^{2}=4.50, p=.03\right)$ by selecting more overhand $(n=115 / 200)$ than underhand $(n=85 / 200)$ grips. Note that DR did not select any uncomfortable final postures.

\subsubsection{Grasping-to-use condition}

Among the three subject groups, only one LBD patient (L2) selected an uncomfortable (thumb-away) grip. Because of the relative infrequency of patients showing uncomfortable (thumb-away) grips, we reported the case of the patient DR.

L2 selected 27 thumb-away grips which were distributed among all items, suggesting the absence of item type effect (Table 2). DR was assessed for both hands. The number of thumbaway grips was smaller for DR than for L2 $\left(n_{\text {left }}=6 ; n_{\text {right }}=7\right)$. Two items were completed by DR without any thumb-away grips ("nutcrackers" and "bottle-opener") and none of the 6 remaining ones were totally failed, confirming the absence of item type effect. Moreover, the number of thumb-away grips selected by DR was similar for both hands indicating the absence of hand effect $\left(\chi^{2}=0.09, p=.87\right)$.

Table 2 about here

Deficits in performing comfortable (thumb-toward) grips might reveal a more general inability to use objects. Despite their abnormal grip selection, DR and L2 used objects in an effective way. However, given their pathological scores in the object use test (control range: 19-20; DR: 18/20; L2: 16/20), object use skills were probably not totally spared in these patients. Other results speak to this issue. More precisely, data obtained from the assessment of effectiveness under the grasping-to-use condition revealed that only two patients (L6 and 
L8) showed a lack of effectiveness in using objects. On 8 out of 64 trials, L6 used objects in an inappropriate manner (all trials "saw"). L8's errors $(n=39)$ were reported for items "saw" $(n=8)$, “wrench" $(n=8)$, "nutcrackers" $(n=8)$, "hammer" $(n=7)$ and "bottle-opener" $(n=$ 8). These two patients were impaired in the object use test (L6: 17/20; L8: 11/20), confirming that their difficulties also occurred in a more natural context of object utilization. Patients L7 and L16 also failed the object use test (14/20 and 17/20, respectively). It is important to note that, despite their difficulties in using objects, these four patients (L6, L7, L8 and L16) did not perform the least uncomfortable (thumb-away) grip.

\subsection{Between-group comparisons}

Because of unequal group sizes and partly unequal variances, between-group comparisons were performed with Kruskal-Wallis ANOVAs. With the exception of object use, all these analyses were significant (all $p s<.03$; Table 1). Post-hoc pairwise analyses with MannWhitney $U$-tests revealed that LBD patients scored significantly lower than controls on object utilization gesture recognition and pantomime production ("sight" and "imitation")(all $p \mathrm{~s}<$ .01). RBD patients performed significantly lower than controls on object utilization gesture recognition. Differences between LBD and RBD patients were non-significant.

\subsection{Correlations}

Given the low variability of scores on the grasping-to-use condition, estimates of relationships with the other measures were inappropriate and, therefore, they were not performed. Spearman rank correlations were computed separately for each patient group (Table 3). No significant correlation was found for each group between the number of uncomfortable final postures and other measures. The only significant correlations found were in LBD patients between object use and pantomime production ("sight" and "imitation"). 
Table 3 about here

\section{Discussion}

The present study aimed to test the different constraint hypothesis versus the same constraint hypothesis. Our main result was the dissociation between the two conditions of the grip preference test. While several LBD and RBD patients performed uncomfortable final postures in the grasping-to-transport condition, only two patients (L2 and DR) used uncomfortable (thumb-away) grips in the grasping-to-use condition. Importantly, all measures of the general praxis testing were not significantly related to either of the two conditions of the grip preference test. This latter finding contradicts that of Buxbaum et al. (2005) who reported significant correlations between scores of grip selection and pantomime production. However, in this study, the score of grip selection assessed the ability to judge how dowels would be grasped, so that the relationship could reveal a deficient ability to generate mental images.

It has been suggested that grasping an object to transport it (acting on) would involve the selection of postures appropriate for achieving a stable grip for transportation (Johnson-Frey \& Grafton, 2003). The computation of object's physical properties (weight, size), the actor's intention (where the object has to be moved) and possible postures would constrain this selection in a way that minimizes, during transportation, uncomfortable postures - i.e., postures near the extremes of the range of joint motion (Rosenbaum et al., 2001). Our results emphasized the role of both hemispheres in the ability to perform comfortable final postures (see also Steenbergen, Meulenbroek, \& Rosenbaum, 2004). However, it has been pointed that, while the left hemisphere could be directly involved in the grip selection per se, the difficulties encountered by RBD patients could reveal deficits in processing visuo-spatial 
aspects of the task (Hermsdörfer et al., 1999). Unfortunately, our work did not allow further elaboration on this point. Regardless, Hermsdörfer et al.'s (1999) study and ours, taken together, make clear that difficulties to choose the best grip in grasping-to-transport condition are distinct from apraxia.

Using objects as tools or pantomiming their use (acting with) would require activation of gesture engrams (Buxbaum, 2001; Rothi et al., 1991). While our results emphasized that different constraints for grip selection would appear when an object has to be used or moved, they did not support the gesture engram hypothesis. Indeed, although LBD patients scored significantly lower than controls in pantomime production and in object utilization gesture recognition, they generally performed no uncomfortable (thumb-away) grips. Furthermore, our data also indicated that four LBD patients (L6, L7, L8 and L16) could grasp objects in a consistent manner across trials, yet they failed to use objects appropriately in grasping-to-use condition or/and object use test. These intriguing findings contradict the gesture engram hypothesis assuming that patients with difficulties in using objects and/or pantomiming their use should not be able to consistently select the correct grip.

We think that these findings can open theoretical perspectives for investigation of object use disorders. Indeed, the consistency with which the present four LBD patients grasped objects in the grasping-to-use condition suggests that, on the one hand, their gestural performance was normal and, on the other hand, they maintained the intention to analyse objects as potential tools - as generally do brain-damaged patients with object use impairment. These findings emphasize that a core aspect of the human tool use could be the ability to infer potential tools from mechanical relationships between objects. So, it is distinguished from other classes of hand-object interactions, such as object transport, for which physical relationships between the actor and objects would be determinant. This account extends the mechanical inference hypothesis (Goldenberg \& Hagmann, 1998) by 
suggesting that, even when object use is impaired, LBD patients would continue to make "logical reasoning" that could be extracted from performance.

\section{References}

Bergego, C., Pradat-Diehl, P., Deloche, G., Durand, E., \& Lauriot-Prevost, M.-C. (1992). Apraxie idéatoire et reconnaissance de l'utilisation des objets. Revue de Neuropsychologie, 2, 193-206.

Buxbaum, L.J. (2001). Ideomotor Apraxia: A call to action. Neurocase, 7, 445-448.

Buxbaum, L.J., Johnson-Frey, S.H., \& Bartlett-Williams, M. (2005). Deficient internal models for planning hand-object interactions in apraxia. Neuropsychologia, 43, 917-929.

Goldenberg, G. (1999). Matching and imitation of hand and finger postures in patients with damage in the left or right hemisphere. Neuropsychologia, 37, 559-566.

Goldenberg, G., \& Hagmann, S. (1998). Tool use and mechanical problem solving in apraxia. Neuropsychologia, 36, 581-589.

Hermsdörfer, J., Laimgruber, K., Kerkhoff, G., Mai, N., \& Goldenberg, G. (1999). Effects of unilateral brain damage on grip selection, coordination, and kinematics of ipsilesional prehension. Experimental Brain Research, 128, 41-51.

Johnson-Frey, S.H., \& Grafton, S.T. (2003). From "acting on" to "acting with": The functional anatomy of action representation, In C. Prablanc, D. Pélisson, \& Y. Rossetti (Eds.), Progress in brain research (pp. 127-139). New York: Elsevier.

Rosenbaum, D.A., Marchak, F., Barnes, H.J., Vaughan, J., Slotta, J., \& Jorgensen, M. (1990). Constraints for action selection: Overhand versus underhand grips. In M. Jeannerod (Ed.), Attention and Performance XIII (pp. 321-342). Hillsdale: Erlbaum.

Rosenbaum, D.A., Meulenbroek, R.J., Vaughan, J., \& Jansen, C. (2001). Posture-based motion planning: Applications to grasping. Psychological Review, 108, 709-734. 
Rosenbaum, D.A., Vaughan, J., Barnes, H.J., \& Jorgensen, M.J. (1992). Time course of movement planning: Selection of handgrips for object manipulation. Journal of Experimental Psychology: Learning, Memory, and Cognition, 18, 1058-1073.

Rothi, L.J.G., Ochipa, C., \& Heilman, K.M. (1991). A cognitive neuropsychological model of limb praxis. Cognitive Neuropsychology, 8, 443-458.

Steenbergen, B., Meulenbroek, R.G.J., \& Rosenbaum, D.A. (2004). Constraints on grip selection in hemiparetic cerebral palsy: Effects of lesional side, end-point accuracy, and context. Cognitive Brain Research, 19, 145-159.

Sunderland, A., \& Sluman, S.M. (2000). Ideomotor apraxia, visuomotor control and the explicit representation of posture. Neuropsychologia, 38, 923-934. 
Table 1

Demographic, clinical and experimental data

\begin{tabular}{|c|c|c|c|c|c|c|c|}
\hline & $\begin{array}{c}\text { LBD } \\
(n=16)\end{array}$ & $\begin{array}{c}\text { RBD } \\
(n=10)\end{array}$ & $\begin{array}{l}\text { Control } \\
(n=35)\end{array}$ & All groups & $\begin{array}{c}\text { LBD } \\
\text { vs } \\
\text { RBD } \\
\end{array}$ & $\begin{array}{c}\text { LBD } \\
\text { Vs } \\
\text { control }\end{array}$ & $\begin{array}{c}\text { RBD } \\
\text { Vs } \\
\text { control } \\
\end{array}$ \\
\hline Gender (no.): W/M & $1 / 15$ & $3 / 7$ & $13 / 22$ & $\chi^{2}=5.24, p=.07$ & - & - & - \\
\hline Handedness: right/left & $16 / 0$ & $10 / 0$ & $32 / 3$ & $\chi^{2}=2.34, p=.31$ & - & - & 一 \\
\hline Months since CVA & $2.6(2.0)$ & $3.1(1.5)$ & - & $t(24)=0.72, p=.48$ & 一 & - & 一 \\
\hline Age (years) & $56.6(17.1)$ & $66.0(16.4)$ & $64.1(16.1)$ & $H=2.98, p=.21$ & - & - & - \\
\hline Education (years) & $10.6(4.1)$ & $8.7(2.4)$ & $10.0(3.3)$ & $H=2.86, p=.23$ & - & - & - \\
\hline $\begin{array}{l}\text { Grasping-to-transport } \\
\text { Comf. final posture (no.) }\end{array}$ & $18.1(2.2)$ & $17.5(1.9)$ & $19.8(0.4)$ & $H=21.66, p<.001$ & $n s$ & $*$ & $* *$ \\
\hline Pantomime "Sight" & $14.1(6.0)$ & $17.9(1.9)$ & $18.5(1.1)$ & $H=7.29, p=.027$ & $n s$ & $*$ & $n s$ \\
\hline Pantomime "Imitation" & $15.9(3.4)$ & $17.9(2.2)$ & $18.6(1.2)$ & $H=8.80, p=.012$ & $n s$ & $*$ & $n s$ \\
\hline Recognition $^{\mathrm{a}}$ & $17.9(2.1)$ & $17.5(2.1)$ & $19.7(0.5)$ & $H=17.39, p<.001$ & $n s$ & $* *$ & $*$ \\
\hline Object use & $18.3(2.7)$ & $19.7(0.5)$ & $19.8(0.4)$ & $H=4.11, p=.128$ & - & - & - \\
\hline
\end{tabular}

Values in brackets are standard deviations. $n s$, non-significant $(p>.05) ; *, p<.01 ; * *, p<.001$.

Between-group comparisons were performed with Kruskal-Wallis ANOVAs, except for "months since CVA" (Student $t$-test), and "gender" and "handedness" ( $\chi^{2}$ analyses). When Kruskal-Wallis ANOVAs were significant, these were followed by pairwise comparisons using Mann-Whitney $U$-tests.

${ }^{\text {a }}$ For RBD patients, $n=6$. Four RBD patients were not asked to complete the object utilization gesture recognition test because of pronounced difficulties in identifying photographs of objects. 
Table 2

Number of comfortable and uncomfortable grips in the grasping-to-use condition in patients L2 and DR

\begin{tabular}{|c|c|c|c|c|c|c|c|c|c|c|}
\hline & & Knife & Saw & Pliers & Spoon & Wrench & Nut-crackers & Hammer & Bottle-opener & Total \\
\hline L2 & Left & $4 / 4$ & $6 / 2$ & $4 / 4$ & $7 / 1$ & $3 / 5$ & $7 / 1$ & $3 / 5$ & $3 / 5$ & $37 / 27$ \\
\hline \multirow[t]{2}{*}{ DR } & Left & $7 / 1$ & $7 / 1$ & $8 / 0$ & $6 / 2$ & $7 / 1$ & $8 / 0$ & $7 / 1$ & $8 / 0$ & $58 / 6$ \\
\hline & Right & $8 / 0$ & $8 / 0$ & $6 / 2$ & $8 / 0$ & $5 / 3$ & $8 / 0$ & $6 / 2$ & $8 / 0$ & $57 / 7$ \\
\hline
\end{tabular}

The left value represents the number of comfortable grips and the right value the number of uncomfortable grips. 
Table 3

Correlations between test results in LBD and RBD patients

\begin{tabular}{|c|c|c|c|c|c|c|c|c|}
\hline & \multicolumn{4}{|c|}{$\operatorname{LBD}(n=16)$} & \multicolumn{4}{|c|}{$\operatorname{RBD}(n=10)$} \\
\hline & Object use & Imitation & Sight & Recog. & Object use & Imitation & Sight & Recog. \\
\hline Pantomime "Imitation" & $.52 *$ & & & & -.19 & & & \\
\hline Pantomime "Sight" & $.68^{*}$ & $.57 *$ & & & -.04 & .37 & & \\
\hline Recognition $^{\mathrm{a}}$ & .43 & .29 & .18 & & .20 & .38 & .77 & \\
\hline Grasping-to-transport & .25 & .25 & .38 & .05 & .58 & .48 & -.18 & .04 \\
\hline
\end{tabular}

${ }^{\mathrm{a}}$ For RBD patients, $n=6 .{ }^{*} p<.05$. 


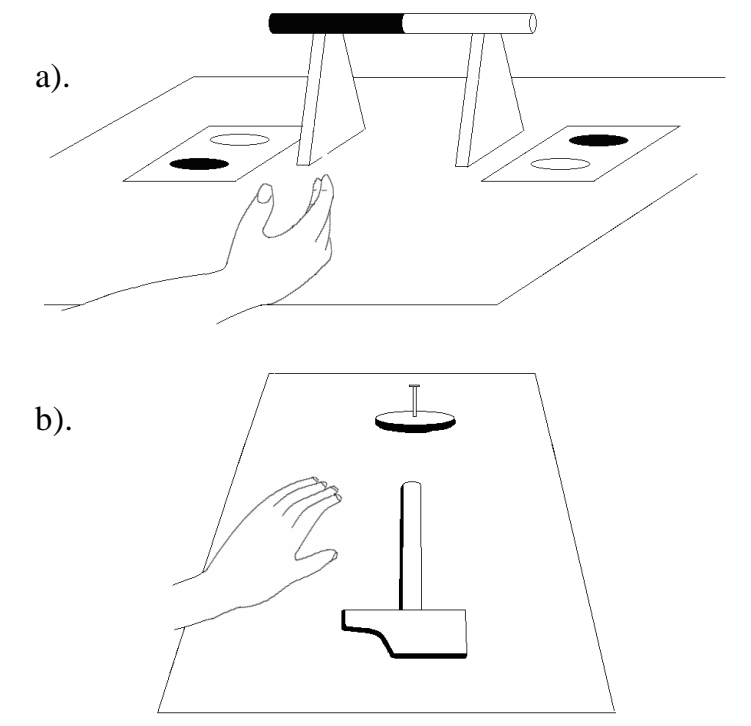

Fig. 1. a). Apparatus used in the grasping-to-transport condition of the grip preference test. The initial hand orientation is shown. b). Apparatus used in the grasping-to-use condition of the grip preference test. The initial hand posture (for participants using their left hand) is shown. The handle of the familiar object points away from the participant. 


\section{Acknowledgment}

We are grateful to Dr. Alaa Ghali for improving the English of the manuscript. 